Portland State University

PDXScholar

2014

\title{
A Test of the Optimal Defense Theory: Cyanogenesis in Phaseolus lunatus $\mathrm{L}$.
}

Lauren M. Stady

Portland State University

Follow this and additional works at: https://pdxscholar.library.pdx.edu/honorstheses

Let us know how access to this document benefits you.

\section{Recommended Citation}

Stady, Lauren M., "A Test of the Optimal Defense Theory: Cyanogenesis in Phaseolus lunatus L." (2014). University Honors Theses. Paper 106.

https://doi.org/10.15760/honors.103

This Thesis is brought to you for free and open access. It has been accepted for inclusion in University Honors Theses by an authorized administrator of PDXScholar. Please contact us if we can make this document more accessible: pdxscholar@pdx.edu. 
A Test of the Optimal Defense Theory: Cyanogenesis in Phaseolus lunatus L.

by

Lauren M. Stady

An undergraduate honors thesis submitted in partial fulfillment of the requirements for the degree of

Bachelor of Science

in

University Honors

and

Micro-/Molecular Biology

Thesis Adviser

Daniel J. Ballhorn

Portland State University 


\section{Acknowledgements}

I would like to express my sincere appreciation to the student members of Dr. Ballhorn's Lab. Your assistance in plant cultivation and in the early stages of laboratory experimentation has been vital in the completion of this thesis. I would also like to thank visiting scientist, Dr. Stefanie Kautz for her clear instruction and patience. I would like to thank Dr. Daniel Ballhorn for allowing me to participate in his laboratory, for his encouragement and support throughout the experimentation and writing process.

I would also like to thank Dr. Ann Marie Fallon for her support in the thesis writing process. Your advice has been invaluable, and greatly appreciated. I would also like to thank Dr. Daveena Tauber for her insightful views on writing. 
Table of Contents

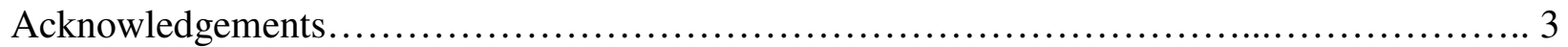

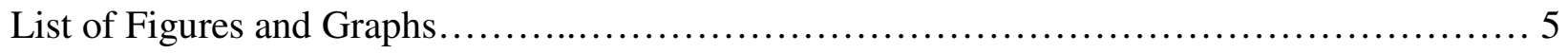

Chapters

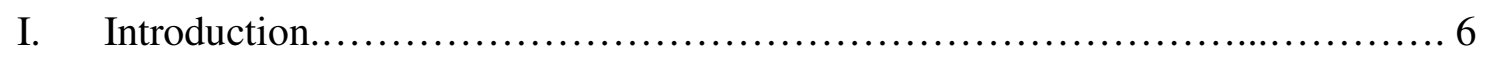

II. Materials and Methods................................................. 11

III. Results............................................................... 16

IV. Discussion...................................................... 18

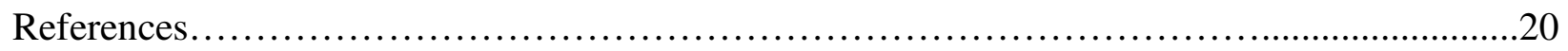




\title{
List of Figures and Graphs
}

\author{
Figures

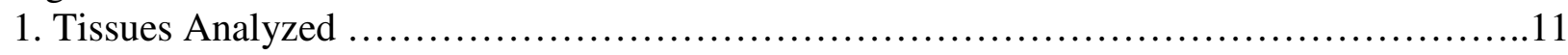

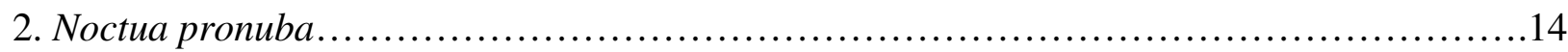

Graphs

1. Quantitative Variability of Chemical Plant Traits .......................................16

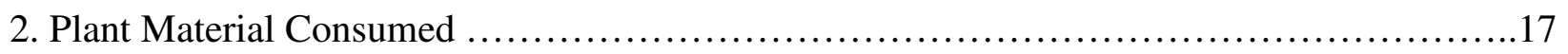


CHAPTER I

Introduction

\section{Background}

Plants show a broad range of chemical defenses against herbivores. Cyanogenesis, the woundinduced release of hydrogen cyanide, is a common direct defense $\mathrm{e}^{1}$. Within a given plant, hydrogen cyanide is not directly stored as free molecular HCN, but as a cyanogenic glycoside. These glycosides exist as cyanide groups attached to sugar moieties. To be used as a chemical defense, a hydrolysis reaction cleaves the cyanide from the sugar by employing catalytic enzymes. Compartmentalization of cyanogenic glycosides and reactive enzymes prevents the cyanogenic plant from damaging itself ${ }^{2}$ while chemical defenses are not being used. In the event of injury to the plant, the containment of the cyanogenic glycosides and enzymes is disrupted, thus allowing for the production of hydrogen cyanide. Hydrogen cyanide is an effective chemical deterrent to animals and insects. Its effects, which can be fatal at low concentrations, operate by inhibiting cellular respiration within the somatic cells of the herbivore ${ }^{3}$, leading to injury or death.

According to the optimal defense theory (ODT), chemical defenses should be allocated to plant tissues most relevant for plant fitness, i.e., young leaves and reproductive structures ${ }^{4}$. Although widely accepted, there is surprisingly little empirical support for the $\mathrm{ODT}^{4}$, in particular for reproductive structures. To evaluate the validity of this theory, we will quantify cyanogenesis, which represents the defensive trait of interest, and soluble proteins, the nutritive traits of multiple plant tissues (leaves, flowers, fruits) and developmental stages in lima bean (CV8078) and test the assumptions of the optimal defense theory ${ }^{4}$. These two parameters are particularly 
important for resulting data interpretation because they represent correlation of defense level by the plant and the associated nutritional value of the same tissue to a predator.

Hydrogen cyanide quantification can be assessed in two separate manners, each of which contributes to a unique view of a plant's overall chemical defense. $\mathrm{HCNp}$, or hydrogen cyanide potential is "the total amount of HCN that can be released from a specific tissue ${ }^{4}$." It represents the plant's potential for protecting itself from predators, but not necessarily the amount of $\mathrm{HCN}$ released upon agitation. The second method of assessment, $\mathrm{HCNc}$, is the capacity for release of hydrogen cyanide over a measured amount of time. This quantity represents when and to what degree the plant defends itself during tissue damage. For the purposes of this experiment, we will only be concerned with the former of the two analytical methods, cyanogenic potential. The methods described in the proceeding section will be conducted with the objective of obtaining information about cyanogenic potential of Phaseolus lunatus ${ }^{5,6}$.

The fundamental goal of our research is to quantify the chemical defense patterns of Phaseolus lunatus and compare our results with the predictions made by the optimal defense theory. We expect to find that relative levels of hydrogen cyanide in plant tissues tested will be in line with predictions made by the optimal defense theory. We also expect to find that the plant tissues with the highest nutritional value will be well protected. Completion of this investigation will provide empirical data to the field of chemical plant defense research. If our findings are congruent with the optimal defense theory, it will lend support to the theory's ability to be used as a general rule for chemical plant defense patterns. 


\section{Overview of the Literature}

The American Naturalist with Doyle McKey as its sole author published the original article first coining the term 'optimal defense' in $1974^{9}$. The article is organized into two main sections, the first of which discusses hypothetical compartmentalization of alkaloid compounds within plant tissue and their molecular characteristics. The second section examines the "optimal use of a limited quantity of chemicals ${ }^{9} . "$ In this section, McKey proposes that in the interest of energy conservation a plant would not store more chemical compounds than is necessary to defend itself, the plant will allocate its chemical resources to plant parts with the consideration of two qualitative characteristics: value and vulnerability. Value of a plant organ is determined by biological fitness. Reproductive organs such as flowers and fruits allow the plant to reproduce and perpetuate its genetic material, thus providing it great biological significance. Vulnerability of a tissue is determined by the organ's susceptibility to attack by herbivorous predators. For example, if young leaves have certain nutritional qualities that are desirable to an animal or insect, the statistical likeliness of the tissue being consumed relative to another organ or similar tissue of different age will determine its vulnerability.

This article is important to our research as it provides the basis from which we make our hypothesis and conduct our experiments.

In the 1992 December volume of Annals of Botany ${ }^{1}$, Australian researcher, Byron Lamont quantifies distribution of cyanogenesis present in Grevillea plant species, a woody plant native to Oceana. Twenty plant parts were tested in this experiment including bark, leaves and ovaries. Lamont is very thorough in his experimentation of the substructures of the flowering tissue, quantifying independently the style, perianth, stigma and buds. This study is unique in that three separate taxa (bipinnatifida, banksii, and Robyn Gordon, an F1 cross of the aforementioned taxa) 
of the Grevillea species are compared lending evidence to evolutionary development of cyanogenesis in closely related taxa. The F1 hybrid of bipinnatifida and banksii has not been influenced by natural selection. Though this plant is sterile, it provides an interesting demonstration of how cyanogenic potency and distribution can change in a single generation of plant species. Results of this experiment lend support to the optimal defense theory in that flowers had the greatest release of HCN compared to any other plant organ. Bipinnatifida and banksii vary in the need for copious seed production as a means of survival of genetic material. Bipinnatifida re-sprouts after fire, while banksii is more susceptible to environmental disturbances and relies heavily on overproduction of seed. That these two plants differ in their modes of survival yet are so closely related and bare high levels of cyanogenic protection in their flowers raises questions of the role of evolution in determination of defense distribution.

In 1996 The American Naturalist published an article by Arthur Zangerl and Claire Rutledge, two researchers from the University of Illinois, Urbana. The article is entitled 'The probability of attack and patterns of constitutive and induced defense: A test of the optimal defense theory. ${ }^{10}$ Zangerl and Rutledge surveyed three populations of wild growing parsnips, Pastinaca sativa $L$. over two summers and recorded actual damage to the plants by herbivores. Pastinaca sativa produces xanthotoxin, an inducible chemical defense of leaves and roots of the plant, and one that is varied in concentration but present as constitutive defense throughout Pastinaca sativa. The researchers report consistency of attack sites between the two years data was obtained; an important observation that led researchers to hypothesize that inducible and constitutive chemical defense will be varied within the plant. Zangerl and Rutledge further hypothesized that two tissues with equal fitness value may have varied constitutive and inducible defenses 
depending on the frequency of herbivore attack. Quantification of xanthotoxin in P.sativa was determined using liquid chromatography and detected with UV light at $254 \mathrm{~nm}$. Results of this experiment showed fruits of $P$. sativa to have the highest levels of constitutive defense, followed by leaves and roots. Results also demonstrate an inverse relationship between inducible defense and constitutive defense. Zangerl and Rutledge explain that because of the selection by herbivores, tissues most likely to be damaged should have the greatest relative constitutive defense, and those attacked least frequently should have greatest inducible defense. This relationship is present because of the 'costliness' of constitutive defense to the plant. This article, unique in its use of a wild plant population, provides empirical support for the optimal defense theory as a predictor of chemical defense patterns. 


\section{CHAPTER II \\ Materials and Methods}

\section{Growth Conditions}

Test plant Phaseolus lunatus was grown in the research greenhouse at Portland State University under the following conditions: $28^{\circ} \mathrm{C} / 22^{\circ} \mathrm{C}, 75-85 \%$ humidity, $14 \mathrm{~h} / 10 \mathrm{~h}$ light/dark photoperiod 5 weeks prior to experimentation. Eight plants per organ tested were used. From each of these plants, three leaf stages were sampled; young, intermediate and mature. Two flower types were also sampled that vary in color with their age ranging from white to light yellow, representing young and old respectively. Fruit pods were sampled based upon their size. The seeds themselves were not be utilized; only the seedpods were used for protein and cyanogenic analysis. Each of these plant organs has been chosen because of its relevance to the optimal defense theory. Please see Figure 1 below for a visual representation of these plant tissues.

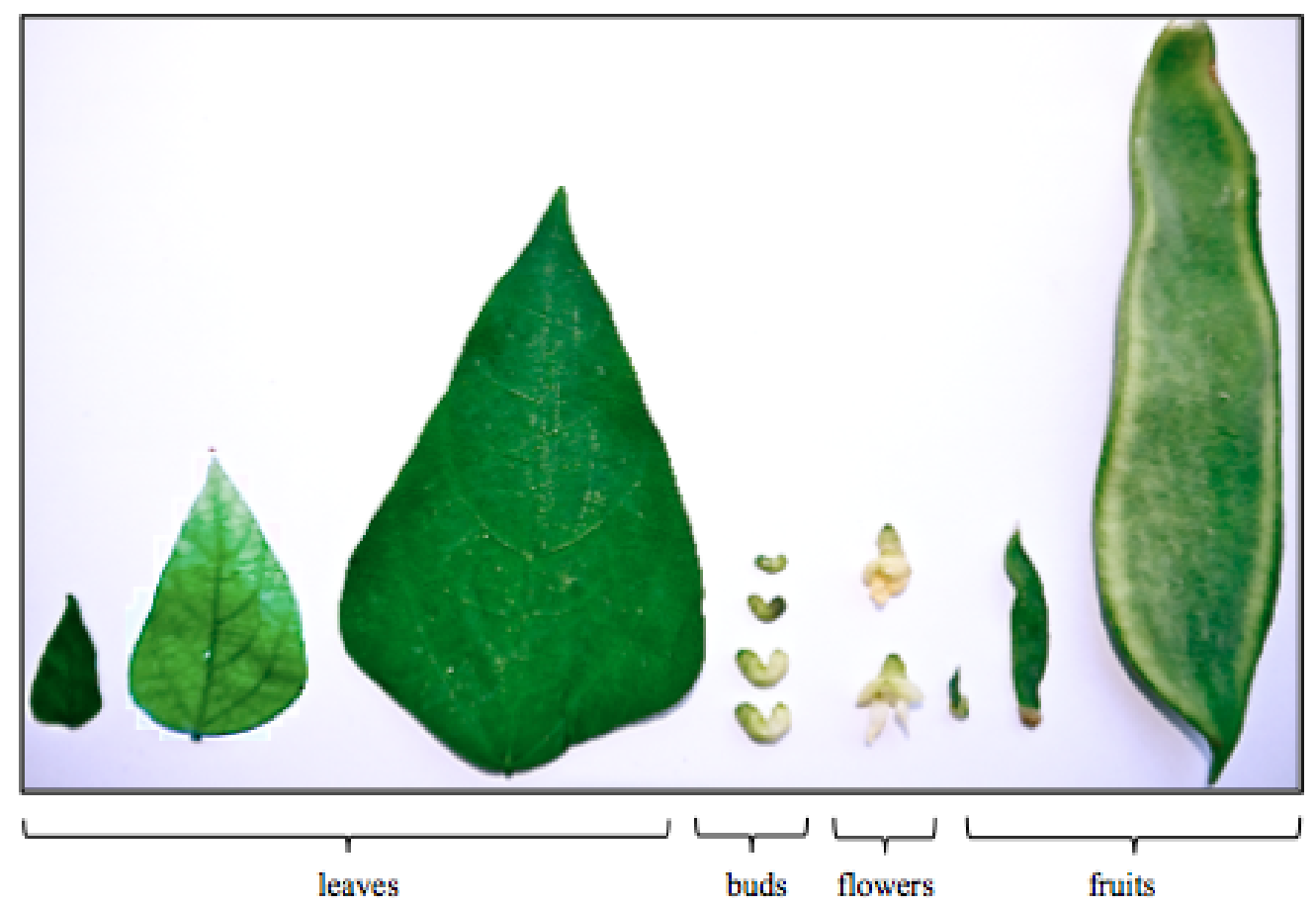

Figure 1. Tissues analyzed. From left to right: Young leaf (inserting three positions down the apex), medium leaf (inserting two positions down from "young"), mature leaf (inserting two stem position down from "medium"), small (top) and large (bottom) flower buds, white flowers (bottom;1-2 days old) and yellow flowers (top; 3-4 days old), young fruit, medium fruit, mature fruit. 


\section{Sampling and Preparation}

Two buckets of ice will be required, one for plant sample transport to inhibit release of volatile organic compounds (VOCs) from being released, and the second for cooling the mortar and pestle. While collecting plant samples, a water bath was prepared for later use at $30^{\circ} \mathrm{C}$, and a centrifuge was cooled to $4^{\circ} \mathrm{C}$. Each sample collected had a corresponding Thunberg vessel, reaction tube and cuvette for sample analysis. Containers are labeled to keep track of samples at each point in the reaction process. Other materials needed are plastic test tube holders, a vortex, and spectrophotometer. The following solutions were set aside and cooled for future use: $0.067 \mathrm{M}$ disodum hydrogen phosphate (Na2HPO4) DiSo Buffer, 0.067M (aq) Sodium dihydrogen phosphate (NaH2PO4) SoDi buffer, 0.2M NaOH, 0.1M HCl. Standard safety precautions were used throughout the duration of the experiment, specifically nitrile gloves when working with caustic reagents.

To begin the quantification procedure, plant samples were chosen in the aforementioned amounts and placed on ice while being transported from the research greenhouse to the laboratory. Using a properly calibrated scale, weight and tissue type and age of the plant samples was obtained and recorded. After weighing, each sample is ground using mortar and pestle with DiSo buffer at an approximate ratio of $2 \mathrm{ml}$ buffer to 1 gram of leaf material. After each sample was ground, the sample was to be transferred to an appropriately labeled $2.0 \mathrm{ml}$ centrifuge tube. Centrifuge was checked for proper cooling at $4{ }^{\circ} \mathrm{C}$ before transferring tubes into the centrifuge. Centrifuge was set for 10 minutes at $13,000 \mathrm{G}$. When complete, a distinct separation between silt-like material and pale green supernatant was observed. Supernatant was used for further analysis, and compacted pellet was discarded. 


\section{Incubation}

Each sample obtained was assigned its own vessel. Assignment and preparation of the following steps was completed during centrifugation. To prepare the Thunberg vessels, each bulb and incubation tube was labeled in the same manner that the previous vessels have been labeled for continuity, including one blank for future calibration. Once labeled, each Thunberg incubation tube was placed in an appropriately sized test tube stand (preferably plastic) with side bulbs removed. $450 \mu \mathrm{l}$ SoDi and $100 \mu \mathrm{l}$ DiSo was pipetted into each tube, including the blank. Labeled side bulbs were prepared by pipetting $600 \mu \mathrm{l}$ of $0.2 \mathrm{M} \mathrm{NaOH}$ into each bulb, then carefully laying it on its side near the corresponding incubation tube.

All samples when not in use were placed on ice. To begin the reaction, $50 \mu 1$ of supernatant from first sample was pipetted into its corresponding labeled vessel from the sample into the incubation chamber, and side bulb was immediately applied. After all samples had been added to reaction tubes in this same manner, test tube rack with Thunberg vessels was moved to heated water bath. Temperature was observed to be $30^{\circ} \mathrm{C}$ before beginning, and was constant throughout incubation. Samples were incubated undisturbed for 20 minutes.

\section{Reaction and Spectrophotometry}

Reaction tubes were prepared while samples were incubating. One reaction tube was used for each sample obtained. Each tube was labeled 1-\#n samples. Into each tube, $4.8 \mathrm{ml}$ distilled and deionized water (aqua dest. from here on) and $100 \mu \mathrm{l} 0.1 \mathrm{M} \mathrm{HCl}$ was added. After incubation was complete, test tube rack was removed from the water bath on to a few sheets of paper towels. Reaction was stopped by inverting each Thunberg vessel 3 times, mixing the side bulb and the incubation tube. This process was repeated with each sample. Once mixed, side bulb was 
removed, and $100 \mu \mathrm{l}$ of each sample from the Thunberg vessels was pipetted into its new, appropriately labeled reaction tube. Remainders of the samples were kept on ice for future protein quantification. Next, Spectroquant ${ }^{\circledR}$ cyanide test was performed as per manufacturer instructions ${ }^{11}$. One scoop of components A and B were added separately into the reaction tube with the sample, vortexing thoroughly in between each addition. Two drops of component $\mathrm{C}$ were subsequently added into each reaction tube and vortexed again. Analysis of the samples was completed using a spectrophotometer at a wavelength of $585 \mathrm{~nm} .1 \mathrm{ml}$ of the homogenized mixture was transferred into a cuvette and results were recorded.

Protein analysis ${ }^{8,9,12}$ was completed using the remaining samples stored on ice. Analysis was conducted as per the Bradford Method ${ }^{12}$. New cuvettes were made for each tissue sample. To each cuvette, $1 \mathrm{~mL}$ of diluted bovine serum (1 part serum to 5 parts water) to $20 \mu \mathrm{L}$ of sample was added. Samples were incubated for 5 minutes. Spectrophotometer was recalibrated to $595 \mathrm{~nm}$, and all results were recorded.

\section{Feeding Trials}

Generalist caterpillar Noctua pronuba (Figure 2 below) was used in feeding trials of Phaseolus lunatus to determine herbivore preference. Tissue type and amount consumed were observed.

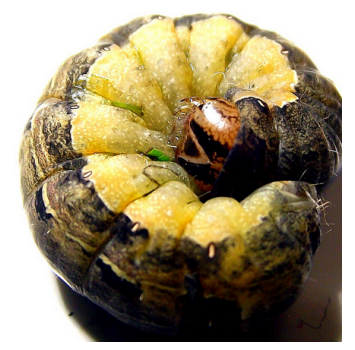

Figure 2. Noctua pronuba generalist herbivore. photo credit: Renaud Torres ${ }^{7}$.

Caterpillars were reared from eggs collected in Portland, OR (Raleigh Hills) in July 2012. All caterpillars were derived from a single clutch and fed with acyanogenic raspberry leaves to avoid any adaptations to cyanide-containing nutriments. Feeding trials were conducted in Petri dishes 
lined moist with filter paper. Pre-weighed plant leaf samples (leaf discs, $1.5 \mathrm{~cm}^{2}$ ), buds, flowers and fruits were offered simultaneously to the insects ( $3^{\text {rd }}$ larval stage) over a time period of $2 \mathrm{hr}$. Consumption was determined by re-weighing the plant samples. 


\section{CHAPTER III}

Results

\section{Cyanogenic potential}

Leaves showed the highest HCNp values, followed by fruits and flowers. Young leaves (66.40 \pm $3.15 \mu \mathrm{mol} \mathrm{HCN} \mathrm{g}{ }^{-1} \mathrm{fw}$ ) accumulated more cyanide than all other organs (Fig. 3A). For each type of organ, youngest developmental stages consistently had higher HCNp than older organs. The same pattern was observed for soluble protein concentration with youngest parts having the highest and oldest the lowest concentrations (Fig. 3B). Consequently, the HCN/protein ratio mirrored both the quantitative distribution of HCNp and protein in lima bean plants (Fig. 3C).
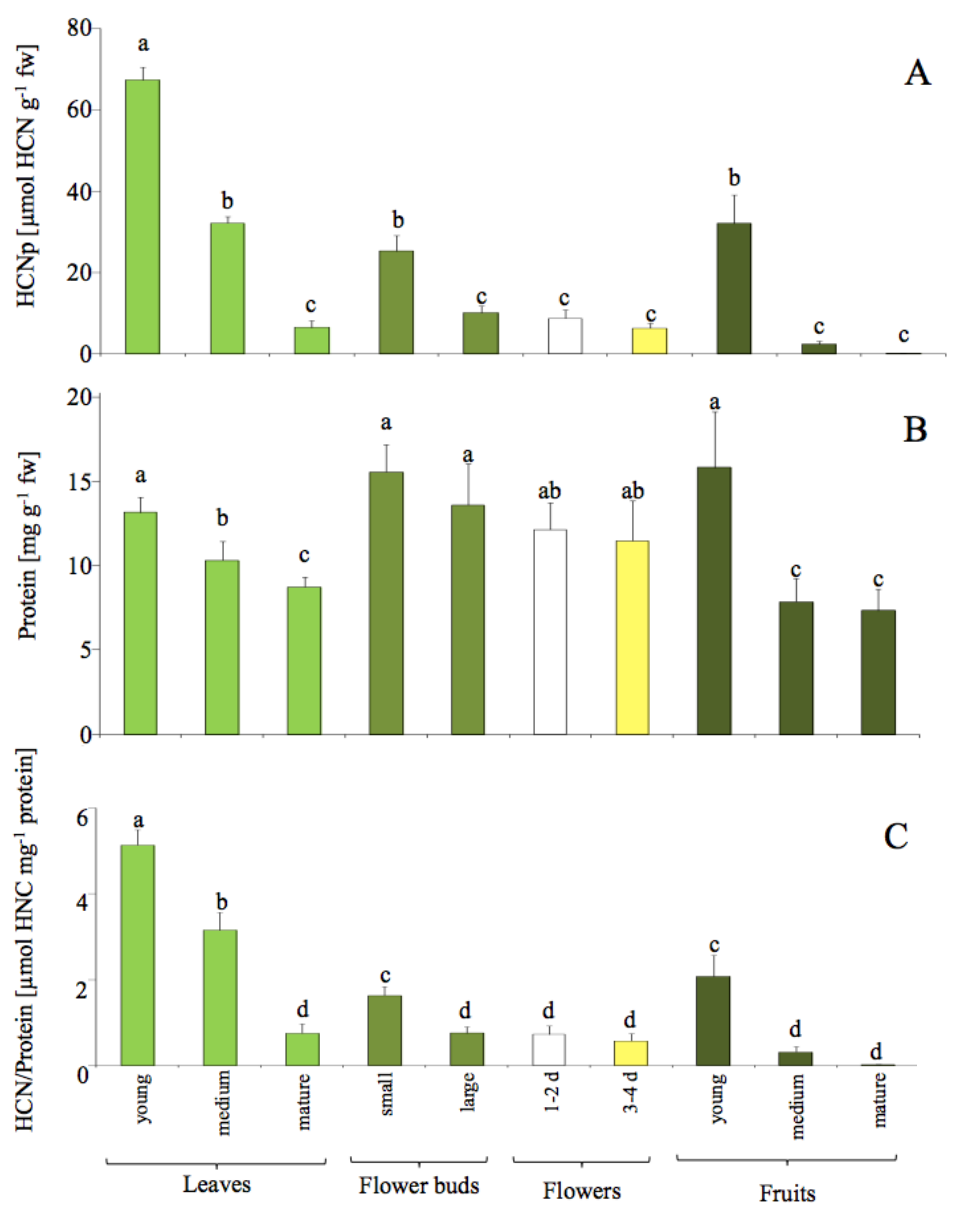

Fig. 3. Quantitative variability of biochemical plant traits. A) Cyanogenic potential (HCNp); B) soluble protein; C) $\mathrm{HCNp}$ /protein. Bars represent means $+\mathrm{SD}$. $\mathrm{N}=8$ per plant organ. Significant differences between organs were calculated by a post hoc test (LSD; $\mathrm{P}<0.05)$ after one-way ANOVA and are indicated by different letters at the columns. 


\section{Feeding Trials}

Flowers of both age groups were the most highly consumed plant tissue. Second most consumed tissues were large flower buds and medium fruit pods. All other tissues were consumed at statistically indistinguishable amounts. Flowers of both age groups were in the lowest statistical grouping for HCNp, and were relatively high in protein content as shown in Figure 3 above.

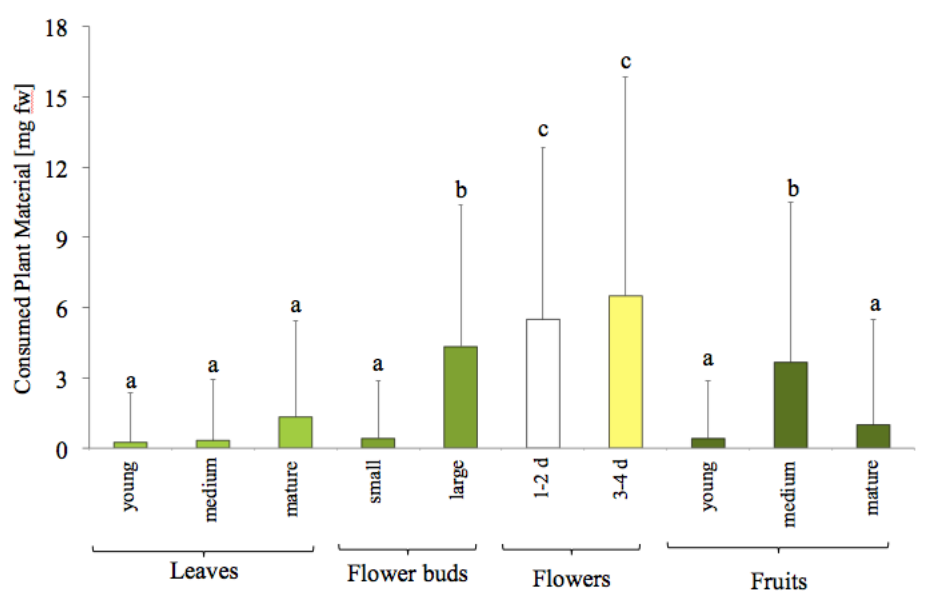

Figure 4. Plant Material Consumed. Resultant data of feeding trial Bars represent means $+\mathrm{SD}$. $\mathrm{N}=8$ per plant organ. Significant differences between organs were calculated by a post hoc test (LSD; P < 0.05) after one-way ANOVA and are indicated by different letters at the columns. 


\section{CHAPTER IV}

Discussion

\section{Significance}

Youngest tissues from all organs exhibit highest $\mathrm{HCNp}$ values (Fig.3 A), with each subsequent age group showing successive decreases in chemical defense. These values also indicate that young leaves in particular are better protected than reproductive structures (i.e. buds, flowers and fruits). Though the optimal defense theory (ODT) does predict young tissues to be of greatest value to the plant, the relatively little protection allotted to reproductive structures of all stages is in contrast to predictions made by ODT. The trend identified above in HCNp values is similar to that of soluble protein concentration. High concentrations of protein are found in youngest tissues, which continue to decrease as the specific organ matures (Fig.3 B). The HCN/protein ratio (Fig. $3 \mathrm{C}$ ) represents a nutritionally important parameter as the availability of protein in the food plant critically affects the actual toxicity of cyanide. In particular, the proteinogenic sulfurcontaining amino acids methionine and cysteine are necessary for the enzymatic degradation of cyanide in digestive systems of many herbivores. ${ }^{8}$ High levels of hydrogen cyanide accompanied by low concentrations of protein can produce particular high toxicity in herbivores, whereas the efficacy of relatively low cyanide concentration as plant defense is dramatically reduced when accompanied with high protein content. ${ }^{8}$ Thus, our findings of low HCN/protein ratio in reproductive structures of lima bean are in contrast to the ODT, which predicts a particularly high defense of these tissues. In feeding trials, (Fig.4) an inverse relationship between $\mathrm{HCN} /$ Protein ratio and plant tissue consumption is observed. Blooming flowers were most highly consumed followed by large flower buds, both essential organs that determine biological fitness i.e. reproductive capability of the plant. 


\section{Future Studies}

Results of this study support predictions made by the optimal defense theory in that young tissues are apportioned increased chemical defenses relative to mature tissues. However, the prediction that plant organs relevant for biological fitness will also be well defended is not supported by results of this study. Reproductive structures were among the least protected and most highly consumed tissues in feeding trials. Further experimentation will be required to determine the value of buds and flowers and the possible compensatory response exhibited by the plant in response to consumption by herbivorous insects. Using blooming plants, we plan to remove varying numbers of sexual organs from test plants and record the number of seeds produced by these plants. The lack of protection of flowers and buds may indicate that destruction of reproductive organs is not a limiting factor to the amount of offspring (seeds) that are produced.

\section{Conclusions}

At present, we cannot say with confidence that the optimal defense theory can be used as a generalization of chemical defense patterns for all plants, and more specifically for Phaseolus lunatus. Contrary defense patterns of a single species, however does not negate its value as a means of explanation for patterns shown in other plant species. The best test of the validity of the optimal defense theory would be one that spans many genera of plants and includes feeding trials using herbivores that have co-evolved with the plant of interest. 


\section{References}

1. Lamont, B. Injury-induced cyanogenesis in vegetative and reproductive parts of two Grivellia species and their F1 hybrid. Annals of Botany, 1992. 71: 537-542

2. Lambers, H. Plant Physiological Ecology, 2008. 2ED. 445-460

3. Jones et. al A re-examination of the reactions of cyanide with cytochrome c oxidase. $\mathrm{J}$.

Biochemistry, 1984. 220: 57-66

4. Ballhorn, D.J. et al. Plant cyanogenesis of Phaseolus lunatus and its relevance for herbivoreplant interaction: The importance of quantitative data. Journal of Chemical Ecology, 2005. 31:1445-1473

5. Ballhorn, D.J. et al Comparing responses of generalist and specialist herbivores to different cyanogenic plant features. Entomologica Experimentalis et Applicata, 2010. 134:245-259.

6. Rhoades, D. F. Evolution of plant chemical defense against herbivores. American Association for the Advancement of Science, 1979. 204:166-167

7. Torres, R. photo credit: Noctua pronuba, 2010.

8. Ballhorn, D.J. et al. Quantitative Variability of Cyanogenesis in Cathariostachys madagascariensis-the Main Food Plant of Bamboo Lemurs in Southeastern Madagascar. American Journal of Primatology, 2009. 71:305-315

9. McKey, D. Adaptive Patterns in Alkaloid Physiology. The American Naturalist, 1974. 108:305-320.

10. Zangerl, A. Probability of attack and patterns of constitutive and induced defense: a test of optimal defense theory. The American Naturalist,1996. 147: 599-608

11. Merck Millipore ${ }^{\circledR}$. Cyanide Spectroquant Reagent Test. http://www.merckmillipore.com/INTL/en/product/Cyanide-Test,MDA_CHEM109701\#documentation, 2014.

12. Bradford, M. A Rapid and Sensitive Method for the Quantitation of Microgram Quantities of Protein Utilizing the Principle of Protein-Dye Binding. Analytical Biochemistry, 1976. 72:248254 